\title{
CpG oligodeoxynucleotides induce strong up-regulation of interleukin 33 via Toll-like receptor 9
}

\author{
Takeshi Shimosato $^{a^{*}}$, Megumi Fujimoto $^{b}$, Masanori Tohno $^{c}$, Takashi Sato $^{\mathrm{d}}$, \\ Mariko Tateo ${ }^{\text {, }}$, Hajime Otani ${ }^{b}$, Haruki Kitazawa ${ }^{\mathrm{e}^{*}}$
}

${ }^{a}$ Fiber-Nanotech Young Researcher Empowerment Center, Shinshu University, Minamiminowa, 399-4598, Japan

${ }^{b}$ Graduate School of Agriculture, Shinshu University, Minamiminowa 399-4598, Japan ${ }^{c}$ National Agriculture and Food Research Organization, National Institute of Livestock and Grassland Science, Nasushiobara 329-2793, Japan

${ }^{d}$ Graduate School of Medicine, Yokohama City University, Yokohama 236-0004, Japan ${ }^{e}$ Food Immunology Group, Graduate School of Agricultural Science, Tohoku University, Sendai, 981-8555, Japan

\section{${ }^{*}$ Corresponding authors}

Takeshi Shimosato: Fiber-Nanotech Young Researcher Empowerment Center, Shinshu University, 8304 Minamiminowa, Kamiina, Nagano 399-4598 Japan. e-mail: shimot@shinshu-u.ac.jp, Phone/Fax: +81-265-77-1403, Haruki Kitazawa: Graduate School of Agricultural Science Tohoku University 1-1 Tsutsumidori, Amamiyamachi, Aobaku, Sendai, Miyagi 981-8555, Japan. E-mail: haruki@bios.tohoku.ac.jp; Phone: +81-22-717-8713; Fax: +81-22-717-8715 


\section{Abstract}

We previously reported the strong immunostimulatory effects of a CpG oligodeoxynucleotide (ODN), designated MsST, from the lacZ gene of Streptococcus (S.) thermophilus ATCC19258. Here we show that $24 \mathrm{~h}$ of stimulation with MsST in mouse splenocytes and peritoneal macrophages strongly induces expression of interleukin (IL)-33, a cytokine in the IL-1 superfamily. Other IL-1 superfamily members, including IL-1 $\alpha$, IL-1 $\beta$ and IL-18, are down-regulated after $24 \mathrm{~h}$ of stimulation of MsST. We also found that MsST-induced IL-33 mRNA expression is inhibited by the suppressive ODN A151, which can inhibit Toll-like receptor 9 (TLR9)-mediated responses. This is the first report to show that IL-33 can be induced by CpG ODNs. The strong induction of IL-33 by MsST suggests that it may be a potential therapeutic ODN for the treatment of inflammatory disease. The presence of a strong CpG ODN in S. thermophilus also suggests that the bacterium may be a good candidate as a starter culture for the development of new physiologically functional foods.

Keywords: IL-33, CpG-ODN, TLR9, IL-1 superfamily, Streptococcus thermophilus 


\section{Introduction}

One or more cellular component of Streptococcus thermophilus can lead to increased intestinal barrier capacity and T helper type 1 (Th1) immune responses in host cells, highlighting the role of lactic acid bacteria (LAB)-derived components in inducing host defense (1). Previously, we identified an immunostimulatory sequence of oligodeoxynucleotides (ISS-ODNs) present in the $S$. thermophilus lacZ gene that can induce a strong response. The ODN consists of a CpG sequence motif and was designated MsST (2). We observed significant up-regulation of interleukin (IL)-10 expression in mouse splenocytes after stimulation with MsST (2). Related to this, the results of studies in mice indicate that IL-10 can suppress the development of eosinophilic inflammation in airways (3).

Recently, IL-33, a new anti-inflammatory cytokine, was identified as a functional ligand for the mouse ST2 receptor $(4,5)$. IL-33 binds to the ST2 receptor present on mast cells (6) and Th-2 cells (7). ST2 is thought to mediate the biological activity of IL-33, resulting in a Th2-biased allergic inflammation. Both in vivo and in vitro, IL-33 can enhance production of Th2-associated cytokines such as IL-4, IL-5, and IL-13 via polarization of Th2 cells $(4,8,9)$. Thus, IL-33 is currently recognized as a potentially important cytokine that enhances Th2-balanced immune regulation. Similar to IL-1 and IL-18, IL-33 is translated in a precursor form that requires caspase-1 cleavage to generate the mature, active form. However, IL-33 is unique in that caspase-1 cleavage can also inactivate IL-33 (10). 
The nuclear targets of IL-33 are still unknown. However, several lines of evidence, such as expression of IL-33 in inflamed tissues, nuclear repressor activity of IL-33 and the antagonistic properties of IL-33 against ST2, suggest that IL-33 may lead to decreased inflammation, opposing the activity of factors like IL-1. IL-33 has potential as a novel therapeutic target for the treatment of autoimmune and inflammatory diseases (11). Moreover, in the context of cross-talk between danger-associated molecular pattern protein (DAMP) receptors and pathogen recognition receptors, IL-33 might not only drive Th2 responses via ST2, but also antagonize Toll-like receptor (TLR)-driven proinflammatory responses. Brint et al. (12) demonstrated that cross-linking of ST2 sequesters the adaptor proteins Mal and MyD88 from TLR4, inhibiting the activation of NF-kB and the subsequent expression of proinflammatory cytokine genes. As described in a previous report, we observed a significant up-regulation of IL-10 expression after stimulation with MsST (2). IL-10 exerted both anti-inflammatory and immunoregulatory activities (13). However, there is no evidence of an anti-inflammatory response after IL-33 increase following treatment with CpG ODNs, which act via TLR9. Therefore, in this study, we focused on induction of IL-33 by CpG ODNs and examined the effects of MsST stimulation on mouse splenocytes and peritoneal macrophages.

\section{Materials and methods}

\section{Mice}

Pathogen-free male C57BL6 mice (5 weeks of age) were purchased 
from Japan SLC (Shizuoka, Japan) and kept under temperature and light controlled conditions. Mice were given a standard diet of Labo MR Breeder (Nihon Nosan Co., Kanagawa, Japan) and sterile water ad libitum. Mice were used for study at 8 weeks of age. All experimental procedures were carried out in accordance with the Regulations for Animal Experimentation of Shinshu University and the animal protocol was approved by the Committee for Animal Experiments of Shinshu University. Based on the national regulations and guidelines, all experimental procedures were reviewed by the Committee for Animal Experiments and finally approved by the president of Shinshu University.

\section{Reagents}

Endotoxin-free phosphorothioate ODNs were synthesized by OPERON (Tokyo, Japan). The ODNs were reconstituted in endotoxin-free water and passed through a $0.22 \mu \mathrm{m}$-pore microfilter (Nihon Millipore K.K., Tokyo, Japan). Cells were treated with an equimolar mixture of CpG ODN 1555 (5'-GCTAGACGTTAGCGT-3') (14), control ODN 1612 (5'-GCTAGAGCTTAGGCT-3') (14), MsST from S. thermophilus (5'-CAGGACGTTGTATCACTGAA-3') (2), ID35 from Lactobacillus (L.) rhamnosus GG (5'-ACTTTCGTTTTCTGCGTCAA-3')(15), OLLB7 from L. bulgaricus NIAI B6 (5'-CGGCACGCTCACGATTCTTG-3') (16), or the suppressive ODN A151 (5'-TTAGGGTTAGGGTTAGGGTTAGGG-3') (17). A151 is found in mammalian telomeres and acts by disrupting colocalization of $\mathrm{CpG}$ ODNs with TLR9 in endosomal vesicles without affecting cellular binding and 
uptake (18). Pam3CSK4, Polyinosine-polycytidylic acid (poly(l:C)), Gram-negative lipopolysaccharide (LPS) from Escherichia coli O111:B4, and imiquimod were purchased from InvivoGen (CA, USA).

\section{Cells and cell culture}

Mouse splenocytes were prepared using standard methods (19). Mouse peritoneal macrophages were collected from anesthetized mice by peritoneal lavage with $5 \mathrm{~mL}$ of phosphate-buffered saline, centrifuged at $200 \times g$ for 5 min, resuspended in RPMI complete 1640 medium (Sigma, MO, USA) supplemented with $10 \%$ fetal calf serum (FCS; Sigma), $100 \mathrm{U} / \mathrm{ml}$ penicillin, 100 $\mu \mathrm{g} / \mathrm{ml}$ streptomycin, $25 \mathrm{mM}$ HEPES, $1.0 \mathrm{mM}$ sodium pyruvate, nonessential amino acids, and $0.0035 \%$ 2-mercaptoethanol. More than $98 \%$ of the adherent cells were considered to be macrophages based on four criteria described previously (20). Mouse peritoneal macrophages were preincubated and adhered to dishes in media for $24 \mathrm{~h}$ before exposure to ODNs. Cells were cultured in medium at a final concentration of $1 \times 10^{6}$ cells per well (total volume, $1 \mathrm{~mL}$ per well).

\section{Real-time quantitative PCR analysis}

Total RNA was isolated from ODN-stimulated mouse splenocytes, treated with RNAse-free DNAse I (Roche, Lewes, UK) for 10 min at $37^{\circ} \mathrm{C}$, and then heat inactivated at $70^{\circ} \mathrm{C}$ for $15 \mathrm{~min}(19,21)$. The cDNAs were prepared by reverse transcription from $1 \mu \mathrm{g}$ of total RNA using a PrimeScript ${ }^{\circledR}$ RT reagent kit 
(Takara Bio Inc., Tokyo, Japan). An equivalent volume of the cDNA solution was used for quantification of various cytokine cDNAs by real-time quantitative PCR using a Thermal Cycler Dice ${ }^{\circledR}$ Real Time System (TaKaRa Bio Inc.). Fluorescent real-time quantitative PCR reactions were performed on SYBR Premix Ex Taq (Takara Bio Inc.) using specific primers, with each reaction containing $5 \mathrm{ng}$ of cDNA in $25 \mu \mathrm{L}$. The $\beta$-actin and IL-1 $\alpha, \mathrm{IL}-1 \beta, \mathrm{IL}-18$ and IL-33 primers were purchased from Takara Bio Inc. The PCR cycling conditions were $10 \mathrm{~s}$ at $95^{\circ} \mathrm{C}$, followed by 40 cycles of $5 \mathrm{~s}$ at $95^{\circ} \mathrm{C}$, and $30 \mathrm{~s}$ at $60^{\circ} \mathrm{C}$. As a control, poly (A)+RNA samples were used as templates to check for the presence of contaminating genomic DNA. The sensitivity of the reaction and amplification of contaminant products such as the extension of self-annealed primers were evaluated by amplifying serial dilutions of the cDNA. For cross-sample comparison of results obtained following various treatments, cytokine mRNA levels were first normalized to mRNA levels obtained for $\beta$-actin. The results represent the means $\pm S D$ of three or four independent experiments.

\section{Cytokine ELISAs}

IL-33 levels in cell culture supernatant $48 \mathrm{hr}$ after various treatments were measured using an enzyme-linked immunosorbent assay (ELISA). IL-33 was quantified by using a commercially available ELISA kit (Quantikine mouse IL-33; R\&D Systems) according to the manufacturer's instructions.

\section{TLR9 blocking assay}


Mouse splenocytes were cultured in triplicate in a 24-well plate (Nalge Nunc International K.K. Tokyo, Japan) with A151 plus 1555 or 1612. Cells were incubated with $3 \mu \mathrm{M}$ ODNs at $37^{\circ} \mathrm{C}$ for $24 \mathrm{~h}$, and expression or secretion of cytokines was detected by real-time quantitative PCR or ELISA as previously described (2).

\section{Injection of ODN into Mice}

Mice were housed in sterile microisolator cages in a barrier environment and treated with an intraperitoneal injection of $400 \mu \mathrm{g}$ ODN of MsST, 1612, A151, or MsST+A151. Mouse splenocytes were harvested $48 \mathrm{~h}$ later and monitored for IL-33 gene expression by real-time quantitative PCR.

\section{Statistical analysis}

The significance of differences between mean and control values was assessed by analysis of variance (ANOVA).

\section{Results}

We first sought to determine the effects on mouse splenocytes of expression of IL-1 family cytokines, which occurs in response to MsST stimulation. To do this, we monitored the expression of four IL-1 family cytokines, IL-1 $\alpha$, IL-1 $\beta$, IL-18 and IL-33 in MsST-stimulated mouse splenocytes by real-time quantitative PCR (Fig. 1). MsST was capable of inducing IL-33 at a concentration of $3 \mu \mathrm{M}$ (Fig. 1A). MsST from S. thermophilus strongly induces 
IL-33 after 24 to $48 \mathrm{hr}$ of stimulation (Fig. 1B), whereas IL-1 $\alpha,-1 \beta$ and IL-18 were down-regulated after the same treatment (Fig. 1C, D, E). Cells treated with ODN ID35 from L. rhamnosus GG had similar levels of IL-33 mRNA (141.04 \pm 10.93$)$ as those treated with MsST (148.57 \pm 13.28$)$ (Fig. 2A). Levels of IL-33 mRNA in cells treated with ID35 and MsST were higher than for those treated with compound 1555 (85.63 \pm 8.68$)$ (Fig. 2A). TLR9 recognizes unmethylated bacterial CpG DNA and initiates a signaling cascade, leading to the production of proinflammatory cytokines (22). To further characterize the IL-33 induction mediated by TLR9, we then analyzed IL-33 mRNA expression in mouse peritoneal macrophages, which express TLR9 at high levels. MsST results in robust up-regulation of IL-33 mRNA levels in mouse peritoneal macrophages as well as in mouse splenocytes (Fig. 2B). Next, we sought to determine if IL-33 mRNA expression could be induced by signaling via other TLRs, such as TLR2, which responds to Pam3CKS4; TLR3, which responds to Poly(I:C); TLR4, which responds to LPS; and TLR7/8, which responds to imiquimod (imidazoquinoline compound) (Fig. 3A-D). Treatment with either Pam3CSK4 $(1 \mu \mathrm{g} / \mathrm{mL})$ or imiquimod $(1 \mu \mathrm{g} / \mathrm{mL})$ significantly induces IL-33 mRNA expression in mouse splenocytes (Fig. 3A, D). The levels of IL-33 mRNA (normalized to $\beta$-actin; see Materials and Methods) after Pam3CSK4 or imiquimod stimulation in mouse splenocytes was $6.99 \pm 2.78$ and $76.64 \pm 12.18$, respectively. Interestingly, treatment with imiquimod induces strong up-regulation of IL-33 mRNA expression (142.67 \pm 16.03$)$, i.e. to levels comparable with induction by MsST (Fig.3E). 
We then used A151, a TLR9 blocker, to examine the dependence of the effects we observed on TLR9. We found that IL-33 mRNA (Fig. 4A) and protein (Fig. 4B) levels were responsive to treatment with CpG irrespective of whether the mouse splenocytes were also treated with A151. However, treatment with A151 significantly inhibits IL-33 induction. Consistent with this, $48 \mathrm{~h}$ after injection, mice injected intraperitoneally with MsST had significantly higher splenocyte levels of IL-33 mRNA than mice treated with both A151 and MsST (Fig. 4C).

\section{Discussion}

IL-33 was originally detected in bronchial epithelial cells, cells of the small airways, fibroblasts, and smooth muscle cells, which is suggestive of a role for IL-33 in the regulation of mucosal organ function (4). IL-33 induces helper T cells, mast cells, eosinophils, and basophils to produce type 2 cytokines. The presence of IL-33 appears to correlate with the inflammatory status of various tissues. For example, Carriere et al. (23) reported elevated levels of IL-33 in several tissues: high endothelial venules from tonsils, lymph nodes, Peyer's patches in vessels from inflamed human tonsils, intestines of patients with Crohn's disease, and the synovium of patients with rheumatoid arthritis.

To the best of our knowledge, there have been no previous reports of induction of IL-33 by CpG ODNs. In this study, we report that imiquimod and CpG ODN strongly induce IL-33 in mice splenocytes via TLR7/8 and 9, respectively, an effect that is not observed for other TLR ligands such as TLR2, 
TLR3 and TLR4. TLR9 directly recognizes viral and bacterial CpG-DNA motifs as ligands, whereas murine TLR7 and human TLR8 sense viral single stranded RNA motifs $(22,24,25)$. TLR7 and TLR8 share high sequence similarity with CpG-DNA-binding TLR9 (26). Moreover, TLR7 and TLR8 appear to be closely related to TLR9 at a functional level, and are involved in recognizing virus-derived single-stranded RNAs or synthetic antiviral compounds, such as imidazoquinoline derivatives. Plasmacytoid dendritic cells (pDCs) express TLR7 and TLR9, which can also be induced by specific ligands (27). Both TLR7/8 and TLR9 are also localized to the endosomal compartment and signal via the adaptor molecules MyD88, IRAK1, and TRAF6, leading to activation of IRF7 and induction of type I interferons (28). Our results therefore indicate a hierarchy in TLR7/8 or TLR9 ligand-mediated up-regulation of IL-33, wherein the selective activation of the single stranded nucleic acid-sensing receptors is contingent upon the more promiscuous sensing of nucleic acids by TLR9 subfamily members, such as TLR7.

CpG ODNs are known to stimulate macrophages and dendritic cells (DCs) to secrete high-mobility group box 1 (HMGB1) protein, a CpG binding protein (29). Extracellular HMGB1 accelerates delivery of CpG ODNs to the receptor, leading to a TLR9-dependent increase in IL-6, IL-12, and TNFa secretion (29). Interestingly, HMBG1 may perform this function only in the context of infection, linking the damage and pathogen detection pathways through cross-talk between the HMBG1 receptor, the receptor for advanced glycation end products (RAGE), and TLRs (30). During the course of an infection, 
HMGB1 released from nearby cells binds to bacterial DNA. By then binding to RAGE on pDCs, HMGB1 presents bacterial DNA to TLR9, a key receptor of pDCs that detects and responds to bacterial DNA by stimulating the production of interferon (IFN). RAGE bound to HMGB1 thus acts as co-receptor for TLR9 in this context. This has important implications for autoimmunity, as HMGB1 also acts as a co-receptor for TLR9 after binding to self-DNA released from dead or dying cells (31). These findings support the classification of HMGB1 and IL-1a as DAMPs, which inform the immune system of cell or tissue damage (32). Based on the similarities among HMGB1, IL-1 $\alpha$ and IL-33, we consider that IL-33 may also be a member of the DAMP protein family.

IL-33 differs from IL-1 $\beta$ and IL-18, which require caspase-1 to generate the mature, biologically active forms of the proteins (23). It is also reported that IL-33 does not require maturation for binding and activation of the IL-33 receptor ST2 (10), and that processing by caspase-3 results in IL-33 inactivation (33). Thus, IL-33 appears to be unique in the IL-1 family in terms of both processing and which domains are biologically active (34). In this study, we found that secreted levels of mature IL-33 protein were responsive to treatment with MsST by ELISA. MsST also led to a significant decrease in expression of the Th2 cytokine IL-4 (data not shown). Full-length IL-33 can enhance production of Th2-associated cytokines via binding to ST2 $(4,10)$. Taken together, our findings suggest that the induction of IL-33 by CpG ODN results in an inhibiton of ST2/IL-33 activation, opposing the activity of various factors, including IL-1 
superfamily proteins. Further precise studies are required to confirm the inhibition.

We speculate that up-regulation of IL-33 in response to exposure to an external stimulus such as MsST may serve as an endogenous danger signal that alerts cells in the innate immune system to tissue damage during bacterial challenge, similar to the prototypical alarmins HMGB1 and IL-1 $\beta$. Our findings suggest that IL-33 is an important regulator that acts on macrophages via TLR9. Although our understanding of IL-33 is currently limited, it seems reasonable to suggest that IL-33 might counterbalance the activities of proinflammatory cytokines such as IL-1 and HMBG1. In conclusion, we found a novel immunoregulatory mechanism mediated by CpG ODNs that induces IL-33. Understanding how IL-33 mediates immunoregulation via MsST activation should help in the development of therapeutic ODNs for treatment of inflammatory disease by the strong induction of IL-33. Exploiting this property may also prove useful in the design and production of new physiologically functional foods.

\section{Acknowledgements}

Financial support for this study was provided by the Special Coordination Funds for Promoting Science and Technology of the Ministry of Education, Culture, Sports, Science and Technology of Japan. The study was also supported in part by a Grant-in-Aid for Young Scientists (B) (No. 20780238) from the Japan Society for the Promotion of Science (JSPS), the Shinshu 
Foundation for Promotion of Agricultural and Forest Science, the Hokuto Foundation for Bioscience and Uehara Memorial Foundation to Dr. T. Shimosato. 


\section{References}

[1] S. Menard, D. Laharie, C. Asensio, T. Vidal-Martinez, U. Candalh, A. Rullier, F. Zerbib, F. Megraud, T. Matysiak-Budnik, and M. Heyman, Bifidobacterium breve and Streptococcus thermophilus secretion products enhance T helper 1 immune response and intestinal barrier in mice. Experimental. Biol. Med. 230 (2005) 749-756.

[2] T. Shimosato, M. Tohno, T. Sato, J. Nishimura, Y. Kawai, T. Saito, and H. Kitazawa, Identification of a potent immunostimulatory oligodeoxynucleotide from Streptococcus thermophilus lacZ. Anim. Sci. J. 80 (2009) 597-604.

[3] M.R. van Scott, J.P. Justice, J.F. Bradfield, E. Enright, A. Sigounas, and S. Sur, IL-10 reduces Th2 cytokine production and eosinophilia but augments airway reactivity in allergic mice. Am. J. Physiol. Lung. Cell. Mol. Physiol. 278 (2000) L667-74.

[4] J. Schmitz, A. Owyang, E. Oldham, Y. Song, E. Murphy, T.K. McClanahan, G. Zurawski, M. Moshrefi, J. Qin, X. Li, D.M. Gorman, J.F. Bazan, and R.A. Kastelein, IL-33, an interleukin-1-like cytokine that signals via the IL-1 receptor-related protein ST2 and induces T helper type 2-associated cytokines. Immunity 23 (2005) 479-90.

[5] M. Gadina, and C.A. Jefferies, IL-33: a sheep in wolf's clothing? Sci. STKE. (2007) 31.

[6] D.R. Moritz, H.R. Rodewald, J. Gheyselinck, and R. Klemenz, The IL-1 receptor-related T1 antigen is expressed on immature and mature mast cells and on fetal blood mast cell progenitors. J. Immunol. 161 (1998) 4866-74. 
[7] M. Lohning, A. Stroehmann, A.J. Coyle, J.L. Grogan, S. Lin, J.C.

Gutierrez-Ramos, D. Levinson, A. Radbruch, and T. Kamradt, T1/ST2 is preferentially expressed on murine Th2 cells, independent of interleukin 4, interleukin 5, and interleukin 10, and important for Th2 effector function. Proc. Natl. Acad. Sci. USA 95 (1998) 6930-5.

[8] L.H. Ho, T. Ohno, K. Oboki, N. Kajiwara, H. Suto, M. likura, Y. Okayama, S. Akira, H. Saito, S.J. Galli, and S. Nakae, IL-33 induces IL-13 production by mouse mast cells independently of IgE-Fc epsilon RI signals. J. Leukoc. Biol. 82 (2007) 1481-1490.

[9] Z. Allakhverdi, D.E. Smith, M.R. Comeau, and G. Delespesse, Cutting edge: The ST2 ligand IL-33 potently activates and drives maturation of human mast cells. J. Immunol. 179 (2007) 2051-4.

[10] C. Cayrol, and J.P. Girard, The IL-1-like cytokine IL-33 is inactivated after maturation by caspase-1. Proc. Natl. Acad. Sci. USA. 106 (2009) 9021-6.

[11] R. Kakkar, and R.T. Lee, The IL-33/ST2 pathway: therapeutic target and novel biomarker. Nat. Rev. Drug. Discovery. 7 (2008) 827-40.

[12] E.K. Brint, D. Xu, H. Liu, A. Dunne, A.N. McKenzie, L.A. O'Neill, and F.Y. Liew, ST2 is an inhibitor of interleukin 1 receptor and Toll-like receptor 4 signaling and maintains endotoxin tolerance. Nat. Immunol. 5 (2004) 373-9. [13] K. Kitagaki, V.V. Jain, T.R. Businga, I. Hussain, and J.N. Kline, Immunomodulatory effects of CpG oligodeoxynucleotides on established th2 responses. Clin. Diagn. Lab. Immunol. 9 (2002) 1260-9. 
[14] S. Klaschik, I. Gursel, and D.M. Klinman, CpG-mediated changes in gene expression in murine spleen cells identified by microarray analysis. Mol. Immunol. 44 (2007) 1095-104.

[15] I.D. Iliev, H. Kitazawa, T. Shimosato, S. Katoh, H. Morita, F. He, M. Hosoda, and T. Saito, Strong immunostimulation in murine immune cells by Lactobacillus rhamnosus GG DNA containing novel oligodeoxynucleotide pattern. Cellular. Microbiol. 7 (2005) 403-414.

[16] H. Kitazawa, H. Watanabe, T. Shimosato, Y. Kawai, T. Itoh, and T. Saito, Immunostimulatory oligonucleotide, CpG-like motif exists in Lactobacillus delbrueckii ssp. bulgaricus NIAI B6. Int. J. Food. Microbiol. 85 (2003) 11-21. [17] T. Sato, T. Shimosato, W.G. Alvord, and D.M. Klinman, Suppressive oligodeoxynucleotides inhibit silica-induced pulmonary inflammation. J. Immunol. 180 (2008) 7648-7654.

[18] I. Gursel, M. Gursel, H. Yamada, K.J. Ishii, F. Takeshita, and D.M. Klinman, Repetitive elements in mammalian telomeres suppress bacterial DNA-induced immune activation. J. Immunol. 171 (2003) 1393-400.

[19] T. Shimosato, T. Kimura, M. Tohno, I.D. Iliev, S. Katoh, Y. Ito, Y. Kawai, T. Sasaki, T. Saito, and H. Kitazawa, Strong immunostimulatory activity of AT-oligodeoxynucleotide requires a six-base loop with a self-stabilized 5 '-C center dot center dot center dot G-3 ' stem structure. Cellular. Microbiol. 8 (2006) 485-495.

[20] K. Taketa, T. Matsumura, M. Yano, N. Ishii, T. Senokuchi, H. Motoshima, Y. Murata, S. Kim-Mitsuyama, T. Kawada, H. Itabe, M. Takeya, T. Nishikawa, K. 
Tsuruzoe, and E. Araki, Oxidized low density lipoprotein activates peroxisome proliferator-activated receptor-alpha (PPARalpha) and PPARgamma through MAPK-dependent COX-2 expression in macrophages. J. Biol. Chem. 283 (2008) 9852-62.

[21] M. Tohno, T. Shimosato, Y. Kawai, H. Aso, S. Ikegami, N. Taketomo, T. Saito, and $\mathrm{H}$. Kitazawa, Advanced molecular immunoassay system for immunobiotic lactic acid bacteria using a transfectant of Toll-like receptor 2. Anim. Sci. J. 78 (2007) 195-205.

[22] H. Hemmi, O. Takeuchi, T. Kawai, T. Kaisho, S. Sato, H. Sanjo, M.

Matsumoto, K. Hoshino, H. Wagner, K. Takeda, and S. Akira, A Toll-like receptor recognizes bacterial DNA. Nature 408 (2000) 740-5.

[23] V. Carriere, L. Roussel, N. Ortega, D.A. Lacorre, L. Americh, L. Aguilar, G. Bouche, and J.P. Girard, IL-33, the IL-1-like cytokine ligand for ST2 receptor, is a chromatin-associated nuclear factor in vivo. Proc. Natl. Acad. Sci. USA. 104 (2007) 282-7.

[24] F. Heil, H. Hemmi, H. Hochrein, F. Ampenberger, C. Kirschning, S. Akira, G. Lipford, H. Wagner, S. Bauer. Species-specific recognition of single-stranded RNA via toll-like receptor 7 and 8. Science. 303 (2004) 1526-9.

[25] S.S. Diebold, T. Kaisho, H. Hemmi, S. Akira, Reis e Sousa C. Innate antiviral responses by means of TLR7-mediated recognition of single-stranded RNA. Science 303(2004) 1529-31.

[26] H. Wagner, The immunobiology of the TLR9 subfamily. Trends Immunol. 25 (2004) 381-6. 
[27] A. Krug, A. Towarowski, S. Britsch, S. Rothenfusser, V. Hornung, R. Bals, T. Giese, H. Engelmann, S. Endres, A.M. Krieg, G. Hartmann. Toll-like receptor expression reveals CpG DNA as a unique microbial stimulus for plasmacytoid dendritic cells which synergizes with CD40 ligand to induce high amounts of IL-12. Eur. J. Immunol. 31 (2001) 3026-3037.

[28] P. N. Moynagh, TLR signalling and activation of IRFs: revisiting old friends from the NF-kappaB pathway. Trends Immunol. 26 (2005) 469-476.

[29] S. Ivanov, A.M. Dragoi, X. Wang, C. Dallacosta, J. Louten, G. Musco, G. Sitia, G.S. Yap, Y. Wan, C.A. Biron, M.E. Bianchi, H. Wang, and W.M. Chu, A novel role for HMGB1 in TLR9-mediated inflammatory responses to CpG-DNA. Blood. 110 (2007) 1970-81.

[30] G. Haraldsen, J. Balogh, J. Pollheimer, J. Sponheim, and A.M. Kuchler, Interleukin-33 - cytokine of dual function or novel alarmin? Trends. Immunol. 30 (2009) 227-33.

[31] J. Tian, A.M. Avalos, S.Y. Mao, B. Chen, K. Senthil, H. Wu, P. Parroche, S. Drabic, D. Golenbock, C. Sirois, J. Hua, L.L. An, L. Audoly, G. La Rosa, A. Bierhaus, P. Naworth, A. Marshak-Rothstein, M.K. Crow, K.A. Fitzgerald, E. Latz, P.A. Kiener, and A.J. Coyle, Toll-like receptor 9-dependent activation by DNA-containing immune complexes is mediated by HMGB1 and RAGE. Nat. Immunol. 8 (2007) 487-96.

[32] M.E. Bianchi, DAMPs, PAMPs and alarmins: all we need to know about danger. J. Leukoc. Biol. 81 (2007) 1-5.

[33] S. Ali, D.Q. Nguyen, W. Falk, M.U.Martin, Caspase 3 inactivates biologically 
active full length interleukin-33 as a classical cytokine but does not prohibit nuclear translocation. Biochem. Biophys. Res. Commun. 391 (2010) 1512-6. [34] A.U. Lüthi, S.P. Cullen, E.A. McNeela, P.J. Duriez, I.S. Afonina, C. Sheridan, G. Brumatti, R.C. Taylor, K. Kersse, P. Vandenabeele, E.C. Lavelle, S.J. Martin. Suppression of interleukin-33 bioactivity through proteolysis by apoptotic caspases. Immunity. 31(2009) 84-98. 


\section{Figure legends}

Figure 1. Analysis of IL-33, IL-1 $\alpha$, IL-1 $1 \beta$, IL-18 mRNA expression in mouse splenocytes. Total RNA was extracted and the relative levels of mRNAs that encode various cytokines were measured by real-time quantitative PCR. (A), MsST was used to determine the optimal concentration of ODNs. (B-E), Mouse splenocytes were pre-incubated in media for $2 \mathrm{~h}$ prior to exposure to $3 \mu \mathrm{M}$ MsST

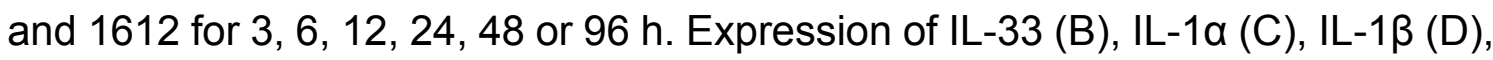
or IL-18 (E) mRNAs was determined by real-time PCR. Results are shown as the ratio of IL-33 mRNA levels (first normalized to a $\beta$-actin; see Materials and Methods) for stimulated versus ODN1612-treated cells. Values represent means and error bars indicate standard deviations. The results represent the means \pm SD of three or four independent experiments. ${ }^{* *}, P<0.01$, or ${ }^{\#}, P<0.01$ as compared with identically treated cells cultured in the presence of ODN1612.

Figure 2. Analysis of IL-33 mRNA expression in mouse splenocytes (A) and peritoneal macrophages (B) by lactic acid bacterial ODNs, ID35, MsST and OLLB7. Positive control, ODN1555, and negative control, 1612. Mouse splenocytes were pre-incubated in media for $2 \mathrm{~h}$ before exposure to $3 \mu \mathrm{M}$ ODNs for $48 \mathrm{~h}$. Items indicated with different letters (i.e. a, b, c) were significantly different $(P<0.01)(A)$. The mouse peritoneal macrophages were preincubated and adhered to dishes in media for $24 \mathrm{~h}$ before exposure to ODNs for $3,6,12$, 24,48 or 96 h. ${ }^{* *} P<0.01$ vs. identically treated cells cultured in the presence of $1612(B)$ 
Figure 3. Analysis of IL-33 mRNA expression in mouse splenocytes. Mouse splenocytes were preincubated in media for $2 \mathrm{~h}$ before exposure to PBS, Pam3CSK4 $(0.01,0.1,1$ or $10 \mu \mathrm{g} / \mathrm{mL})(A)$, Poly (I:C) $(0.01,0.1,1$ or $10 \mu \mathrm{g} / \mathrm{mL})$ (B), LPS $(0.01,0.1,1$ or $10 \mu \mathrm{g} / \mathrm{mL})(\mathrm{C})$ or imiquimod $(0.01,0.1,1$ or $10 \mu \mathrm{g} / \mathrm{mL})$ for $24 \mathrm{~h}(\mathrm{D})$. Panel (E), relative IL-33 mRNA levels following MsST stimulation compared with those treated with an optimal concentration of Pam3CSK4 (1 $\mu \mathrm{g} / \mathrm{mL})$, Poly(l:C) $(1 \mu \mathrm{g} / \mathrm{mL})$, LPS $(10 \mu \mathrm{g} / \mathrm{mL})$ or imiquimod $(1 \mu \mathrm{g} / \mathrm{mL})$. Results are shown as the ratio of IL-33 mRNA levels (first normalized to $\beta$-actin; see Materials and Methods) for stimulated versus PBS-treated control cells. Values with letters (i.e. a, b, c, d) were significantly different $(P<0.05)$.

Figure 4. The suppressive ODN A151 down-regulates IL-33 mRNA and protein levels. Supernatants from stimulated cells were collected, and IL-33 mRNA and protein levels were measured by real time quantitative PCR (A) or ELISA (B). Error bars indicate standard error. ${ }^{* *} P<0.01$ and ${ }^{*} P<0.05$ vs. identically treated cells cultured in the presence of 1612. Response of IL-33 mRNA levels to various treatments (C). C57BL6 mice were intraperitoneally injected with $400 \mu \mathrm{g}$

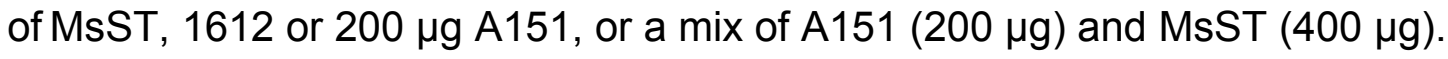
Mouse splenocytes were harvested $48 \mathrm{~h}$ later and monitored for IL-33 expression by real-time quantitative PCR (C). Results are shown as the ratio of IL-33 mRNA levels (first normalized to $\beta$-actin; see Materials and Methods) in stimulated versus PBS-treated control cells. ${ }^{*} P<0.05$ vs. identically treated cells cultured in the presence of 1612. 
Fig.1
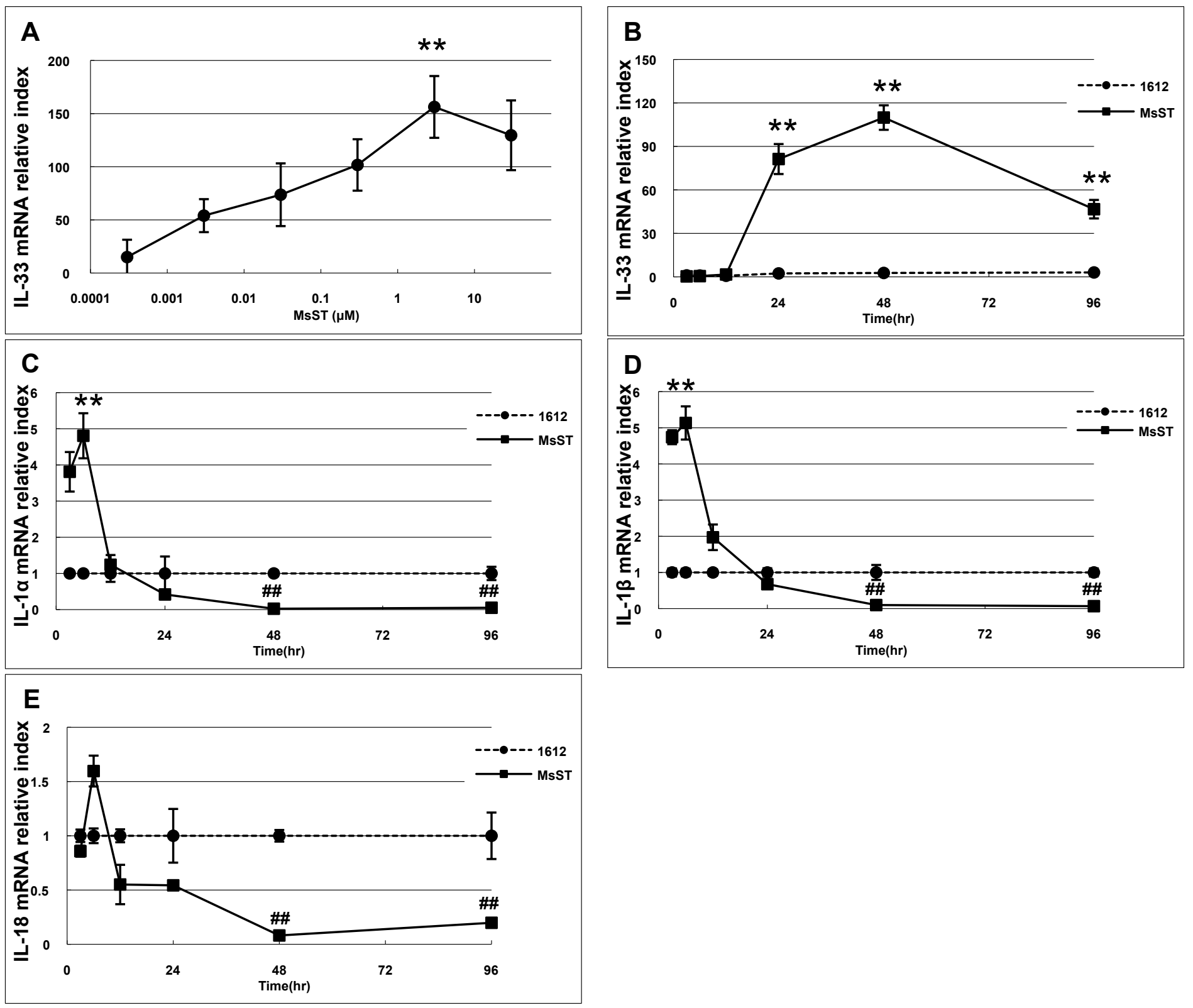
Fig.2
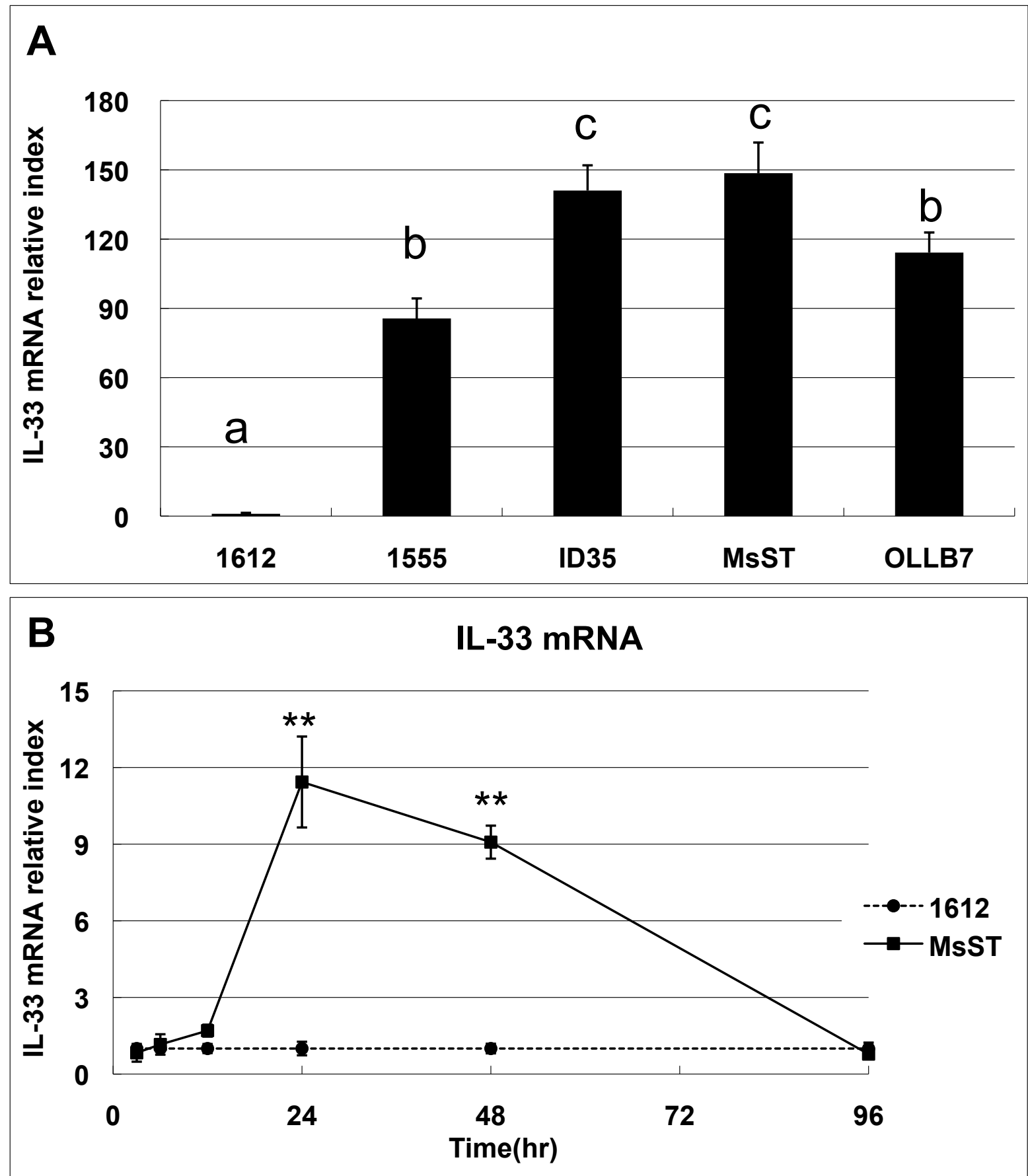
Fig.3
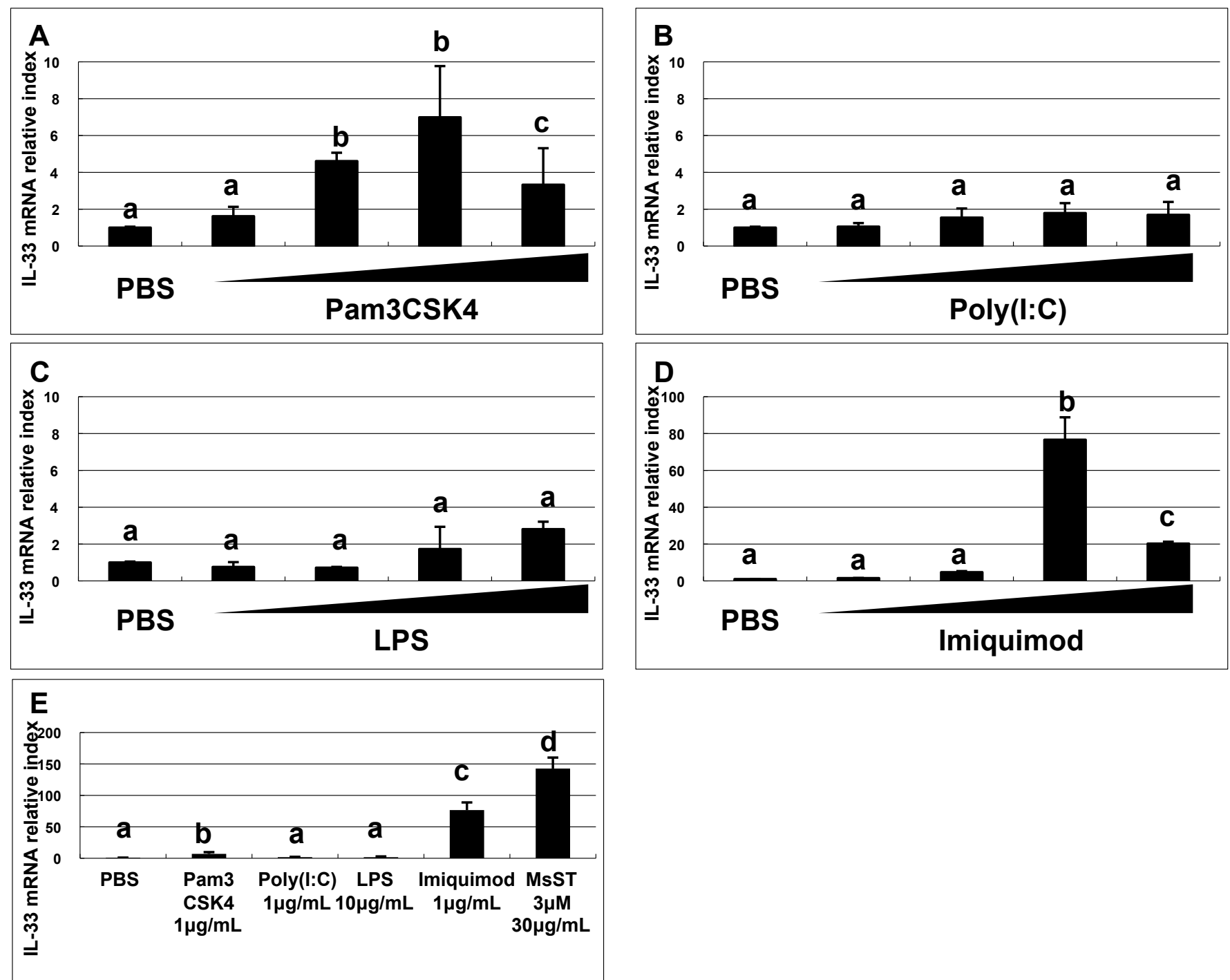
Fig.4
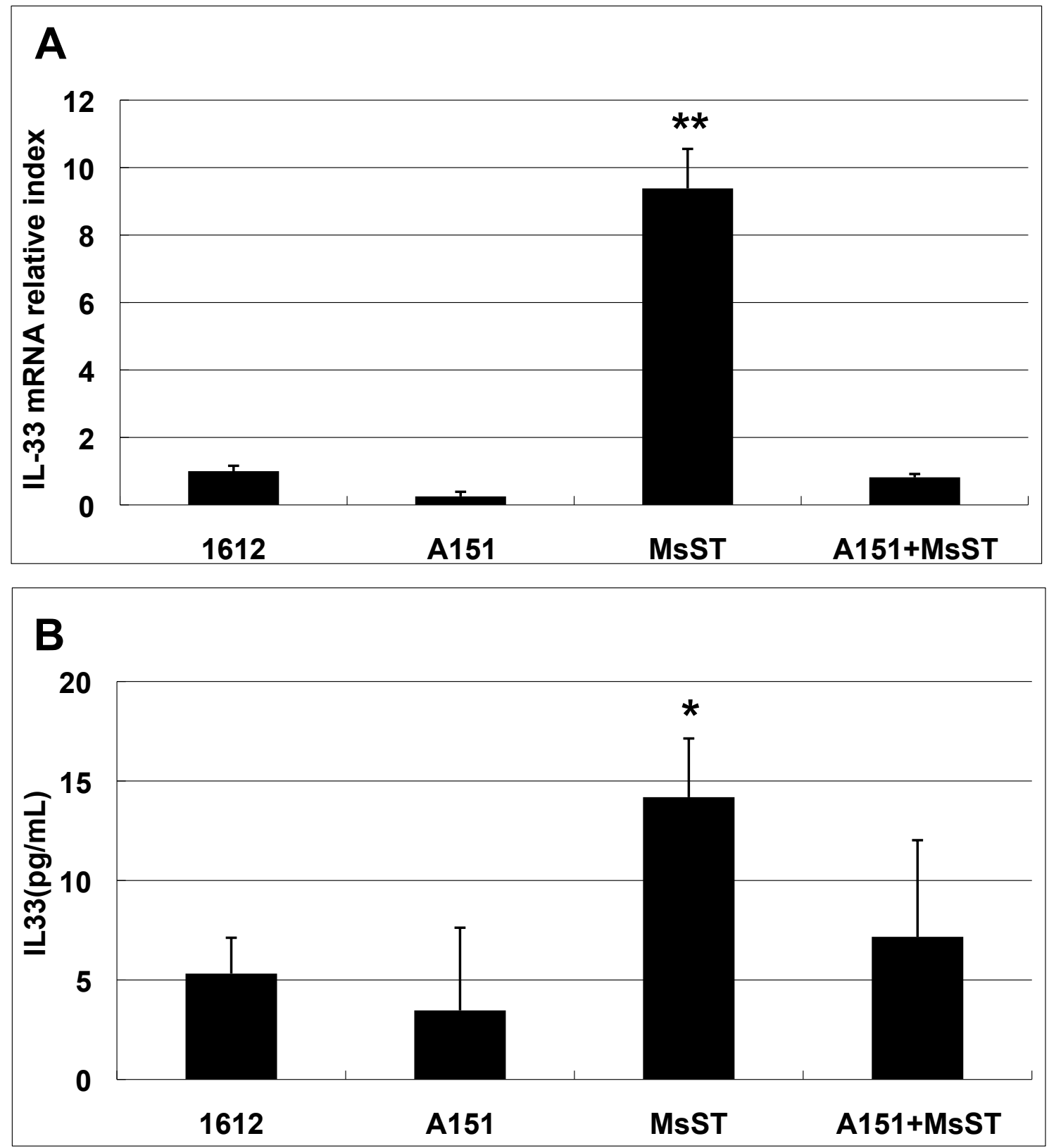

C

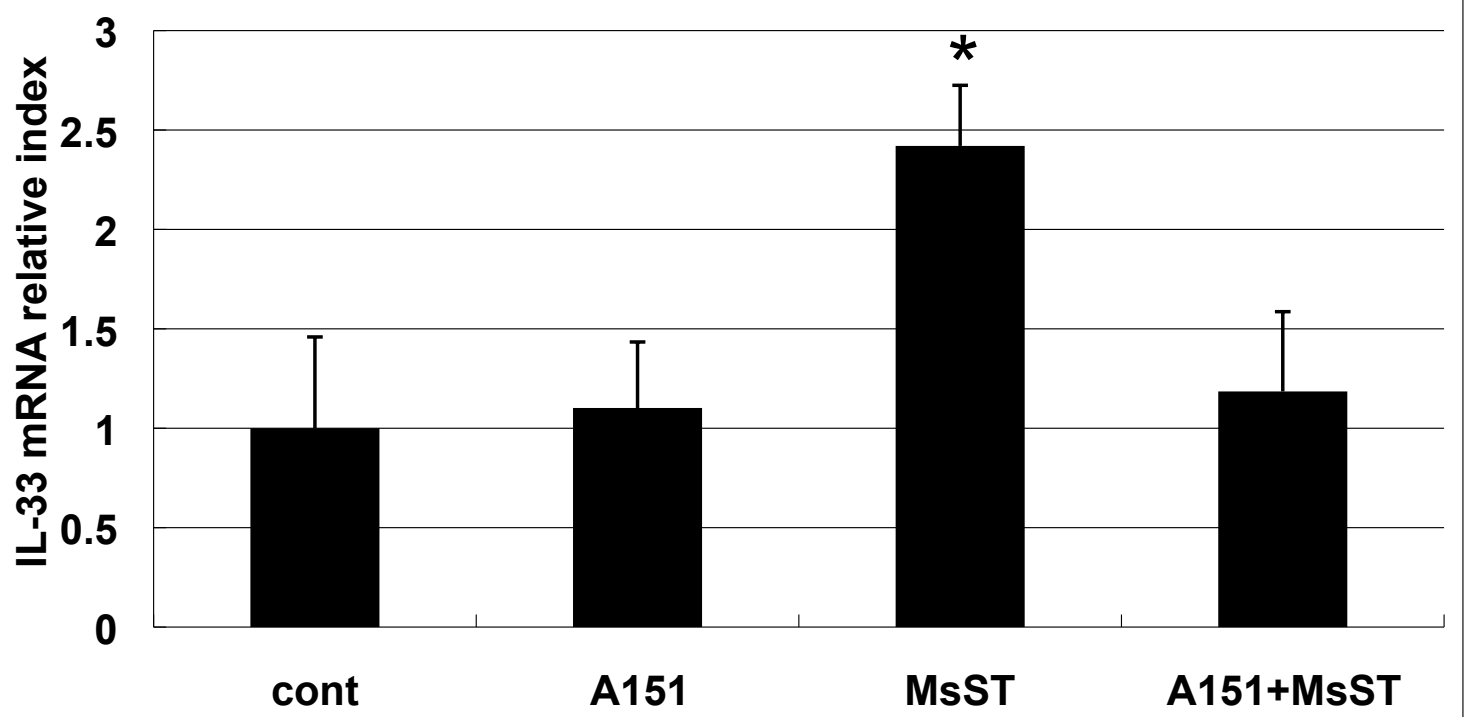

